\title{
EDITORIAL
}

\section{Turf wars in radiology research: "Are the honoraries ready to come out and defend their territory?"}

\author{
Chander Mohan, SM
}

Director, Interventional Radiology, BLK Super Specialty Hospital, Pusa Road, New Delhi, India E-mail: brigcmohan@gmail.com

Every field of science needs continuous innovation and research to maintain its relevance and worth to the society. While doing research to understand complex scientific problems which requires great perseverance and intellect on the part of the researcher, it is prudent for the researcher to be able to disseminate the results of the studies as scientific knowledge for the benefit of the community.

Modern medicine with its ever-increasing diagnostic and therapeutic challenges, in particular, needs this exchange of knowledge where knowledge acquired by one researcher must reach and benefit the entire community. Medical research is slightly different from technological research as the results of these are directly going to impact human life. As a result, it is imperative that the information acquired by one researcher is put to the test by the community, confirmed and validated before the results are applied to the general population.

It takes a long time before any research gets embodied into the scientific knowledge in the form of textbooks or scientific guidelines. During this time, it is imperative that the researchers working in different parts of the world keep sharing their independent research work with each other, which makes research a cohesive rather than an individual experience. Therein lies a huge responsibility of filtering, scrutinizing, and validating the research work which is performed by the reputed scientific journals before knowledge is incorporated into the scientific literature. So in essence the journals have to serve as not just the source of dissemination of this cohesive research but also fulfill the role of watchdogs so that only the useful and unbiased information reaches the community.

As a result, each of these journals have come up with their individual elaborate set of guidelines which every research work has to comply with to ensure consistency, safety, and validity of the information. While this filtering of the information is the major responsibility of the journals, it is imperative that we the physicians also respect our societal and moral obligation to be fair and ethical in our research work. This ethical responsibility has to be fulfilled by the authors and contributors during each and every stage of research.

During the last few decades, there has been a striking rise in the number of scientific journals as well as literature, but along with that there has been a steady increase in the incidents of lapses in the author ethics during the various phases of research. Radiology like any other medical specialty is also amenable to this. Whether this can be attributed to lack of awareness on the part of the researcher or mala fide intentions is a matter of another debate.

Scientific research has traditionally been a matter of personal and professional satisfaction alongside being part of the public responsibility of the physician community. Research articles have long been considered the benchmark of establishing the credentials and expertise of the radiologist in the scientific community. However, the motives and practices of research have evolved to include many other factors in recent years. Now the number of publications one has authored is directly linked to the job profile, remuneration, and taken as an asset to the institute in attracting patients as well as funding for the research. In

This is an open access journal, and articles are distributed under the terms of the Creative Commons Attribution-NonCommercial-ShareAlike 4.0 License, which allows others to remix, tweak, and build upon the work non-commercially, as long as appropriate credit is given and the new creations are licensed under the identical terms.

\begin{tabular}{|l|l|}
\hline \multicolumn{2}{|c|}{ Access this article online } \\
\hline Quick Response Code: & \\
\hline & Website: \\
\hline & www.ijri.org \\
\cline { 2 - 3 } & DOI: \\
\hline
\end{tabular}

Cite this article as: Mohan C. Turf wars in radiology research: "Are the honoraries ready to come out and defend their territory?". Indian J Radiol Imaging 2018;28:1-2. 
fact, now for a radiologist to move forward in an academic background, the lack of publications acts as a road block in his or her professional progress as well as public prestige. This has led to such a striking increase in the volume of research work being submitted to the journals, that these days the major work of the journal editors has become rejection rather than acceptance of most of the work that is being submitted for peer review.

There is a literal rat-race going on in the radiology community to increase the number of publications, with the numbers being the most important criterion for professional progress. This has led to dilution of the quality of published research. Research work is a scientific process which has to adhere to a set of strict protocols and guidelines. The importance of these guidelines is in the fact that the writing procedure forces the writers to analyze the problem in a standardized scientific way. This way of following a set procedure gradually becomes the framework on which any scientific problem in the future can be researched upon and addressed. The radiology curriculum of ours although advocates a research thesis, but this is done more as a rote exercise in most cases rather than a true introduction to research.

Another issue is the funding of the research work. A significant proportion of the research work is being funded by the pharma companies, particularly in developing countries where government funding is on the lower side. This has further led to some unwanted pressures on the researcher to present the results of the research which put the funding company in a profitable position.

Then comes another major consequence of the race for publications - the practice of multiple authorship. Most studies these days have started to have so many authors that most journals have come up with guidelines that you cannot list more than six authors in the bibliography and started the use of "et al." If we look at the journals of today, we are starting to see many articles with "et $a l$ " in the bibliography. First of all, this practice is confusing as the reader is often unable to understand the need for numerous authors. For sure, few complex issues, do need the composite ability of many intellectuals but the outrageous numbers that we are seeing these days of this composite ability are alarming. While the studies in medical and surgical specialty are more likely to be multidisciplinary, the radiology research is carried out mostly in isolation dealing with the results of our diagnostic methods which requires fewer authors in number. In most of these cases, this can be attributed to pleasing the senior faculty in the departments (Gift authorship), sometimes in the need of funding or in other cases simply to give the research more visibility or concealing the commercial motive by associating big names with them (Guest authorship). In fact, the process of adding authors to the bibliography has been on a striking rise for personal or professional gains.
What this has led to is diluting the quality of research as merely adding these "Honorary authors" to the research does nothing profitable to the quality of research. In fact, the resume of many researchers is flush with these "et al" publications. Secondly, this has led to the practice of publishing multiple articles from a single research. While the best effect and usefulness of a research is only where everything pertaining to the topic under research is put together under one article, there has been an alarming trend of many authors trying to split up the core area of research into multiple articles. This is confusing as well as less useful to the scientific community which has to hunt through the vast array of disjointed articles rather than an all-encompassing research about the topic in one place. This has reached to such levels that many studies have co-authors belonging to not just different institutions but also from different cities and sometimes countries.

There has to be a way-out and it is imperative that both the radiologists as well as our employers in the private and public sector put serious thought into this practice. The first thing that can be done is to make the number of citations as the criterion to judge any article which reflects the usefulness of the article to the community at large. We need to stop putting emphasis on the quantity of the publications and stress on the quality of work by using citation as the primary yardstick and ranking author resumes based on it.

The practice of having a principal author is also another practice that can be done away with, as all authors in theory contribute equally to the study and therefore need to be accountable for the study in similar capacity. In essence, any of the co-authors should be allowed to claim the work as their own as well as take responsibility for the same. But this can work only if the practice of "honorary authorship" is stopped.

Another important area is the issue regarding challenge to the autonomy of the radiologist in radiology research as a lot of professionals from other fields such as radiobiologists, radiophysicists, engineers, software programmers, and statisticians are entering radiology research. This is in addition to other physicians who are using radiology modalities like the cardiologists who are already competing with us in radiology research. In fact, most of the research in artificial intelligence software these days is being done by the technology companies rather than only the radiologists themselves.

We need to be mindful of this new facet of "Turf-war" or else we may soon find that radiology research has also been taken away from us like the modality of echocardiography. In short, it is high time that these "Honorary" authors residing in us need to be awakened from this symbolic contribution to perform meaningful and high-quality research or else we may very well be outdone in the "Turf-war" of radiology research soon. 